\title{
Model Averaging and Value-at-Risk based Evaluation of Large Multi Asset Volatility Models for Risk Management*
}

\author{
M. Hashem Pesaran \\ University of Cambridge and USC \\ Paolo Zaffaroni \\ University of Cambridge and Banca d'Italia
}

March 3, 2004

\begin{abstract}
This paper considers the problem of model uncertainty in the case of multi-asset volatility models and argues in favour of the use of Bayesian-type model averaging techniques to deal with the risk of inadvertently using false models in portfolio management. In particular, it is shown that portfolio returns based on an average of Gaussian models with different volatilities is more fat-tailed than an individual Gaussain model with the same average volatility measure. Evaluation of volatility models is also considered and a simple Value-at-Risk (VaR) diagnostic test is proposed for individual as well as 'average' models and its exact and asymptotic properties are established. The model averaging idea and the VaR diagnostic tests are illustrated by an application to portfolios of daily returns based on twenty two of Standard \& Poor's 500 industry group indices over the period January 2, 1995 to October 13, 2003, inclusive.
\end{abstract}

JEL Classifications: C32, C52, C53, G11

Key Words: Model Averaging, Value-at-Risk, Decision Based Evaluations.

*We would like to thank Vanessa Smith for her assistance with the data used in this study. 


\section{Introduction}

Multivariate models of conditional volatility are of crucial importance for optimal asset allocation, risk management, derivative pricing and dynamic hedging. Yet there are few published empirical studies of the performance of multivariate volatility models as applied to portfolios with a relatively large number of assets. Although, many alternative parametric and semiparametric multivariate volatility models have been advanced in the academic literature, until recently most have been limited in the number of assets that they can handle. In an attempt to provide operationally feasible volatility models for the analysis of portfolios with a large number of assets, many investigators (in financial markets as well as in academia) have focused on highly restricted versions of multivariate generalized autoregressive conditional heteroscedastic (GARCH) specification. These include the conditionally constant correlation (CCC) model of Bollerslev (1990), the Riskmetrics specifications popularized by J.P.Morgan/Reuters (1996), and used predominantly by practitioners, the orthogonal GARCH model of Alexander (2001), and more the dynamic conditional correlation (DCC) advanced by Engle (2002). Multivariate volatility models have also been considered in the stochastic volatility (SV) literature. See Ghysels, Harvey, and Renault (1995) and Shephard (2004) for reviews. However, so far the focus of this literature has been on univariate and multivariate models with a small number of assets, with the notable exceptions of Diebold and Nerlove (1989), Engle, Ng, and Rothschild (1990), King, Sentana, and Wadhwani (1994) and Harvey, Ruiz, and Shephard (1994). These models are similar in structure to a class of factor orthogonal GARCH model discussed below.

The highly restricted nature of the multivariate volatility models could present a high degree of model uncertainty which ought to be recognized at the outset. This is particularly important since due to data limitations and operational considerations it is not possible to subject these models to rigorous statistical testing either. Application of model selection procedures also face additional difficulties when the number of assets is moderately large, and might very well be that no single model choice would be satisfactory in practice and could carry risks that are difficult to asses a priori.

In this paper we advocate the use of model averaging in order to minimize the risk associated with model uncertainty. We apply recent developments in model evaluation and model averaging techniques to multi-asset volatility models, in the case where the number of assets under consideration is relatively large. Based on this framework, we develop simple criteria for evaluation of alternative volatility forecasts by examining the Value-at-Risk (VaR) performance of their associated portfolios over an evaluation period. The approach is general and can be applied to strategic asset allocation problems that require volatility forecasts over relatively long periods as well as more traditional VaR problems with horizons ranging from a single day to a month. Our method is relevant both for evaluation of existing portfolios as 
well as for the construction of efficient portfolios.

The probability forecast combination approach also attempts to avoid the pre-testing problem associated with the standard two-stage procedure where the decision problem is based on a probability model selected as the 'best' from a given set of candidate models according to a suitable criteria. Frequently used selection criteria are Akaike Information Criteria (AIC) and the Schwartz Bayesian Information Criteria (SBC). However, such a twostep procedure is subject to the pre-test (selection) bias problem and tends to under-estimate the uncertainty that surrounds the forecast. Second, usually point forecasts are analyzed and the evaluation of their out-of-sample performance is based on standard metrics such as root mean square forecast errors (RMSFE). However, this approach runs into difficulties when considering volatility models. In fact, volatility is not directly observable and is often proxied by square of daily returns or more recently by the standard error of daily returns using intra-daily observations, known as realized volatility (see, for example, Andersen, Bollerslev, Diebold, and Labys (2003)). In multi-asset contexts the use of standard metrics such as RMSFE is further complicated by the need to select weights to be attached to different types of errors in forecasts of individual asset volatilities and their cross-volatility correlations and choice of such weights is not innocuous in a multivariate framework (see Pesaran and Skouras (2002)).

The use of model averaging techniques in econometrics is not new and dates back to the seminal work of Granger and Newbold (1977) on forecast combination. ${ }^{1}$ However, this literature focusses on combining point forecasts and does not address the problem of combining forecast probability distribution functions which is relevant in the risk management literature. The problem is not trivial even in the simplest case of average of normal distributions with different parameters since the average model will not have a normal distribution, except when for the degenerate case of zero-one coefficients.

From a methodological perspective, following Granger and Pesaran (2000b), our approach aims to represent a more unified treatment of the empirical portfolio analysis from a decision-theoretic perspective rather than from a merely statistical one. Granger and Pesaran (2000a) clarify the importance of concentrating on probability forecasts rather than on just event forecasts. Within a risk-management perspective the motivations for doing so appear even stronger since the ultimate goal is not simply to finding the best approximating volatility model but how to best approximate the entire predictive density of asset returns, or at least its tail behaviour.

The remainder of the paper is organised as follows: the decision problem that underlies the VaR analysis and the associated diagnostic tests is set out in Section 2. Section 3 provides a brief outline of the different types of multivariate volatility models considered in the paper. Bayesian and non-Bayesian

\footnotetext{
${ }^{1}$ For reviews of the forecast combination literature see Clemen (1989), Granger (1989), Diebold and Lopez (1996) and Hendry and Clements (2002).
} 
approaches to model averaging are reviewed and discussed in Section 4. Section 5 introduces a simple Value-at-Risk (VaR) diagnostic test and establishes its distribution. Section 6 provides a detailed empirical analysis using daily returns on twenty two of Standard and Poor's 500 industry indices over the period January 21995 to October 13 2003. Section 7 concludes with a summary of the main results and provides suggestions for future research. The mathematical proofs are collected in the Appendix. 


\section{References}

Aiolfi, M., And C. FAvero (2002): "Model uncertainty, thick modelling and the predictability of stock returns," IGIER Working Paper 221, IGIER.

Aiolfi, M., C. Favero, And G. Primiceri (2001): "Recursive 'thick' modeling of excess returns and portfolio allocation," IGIER Working Paper 197, IGIER.

Alexander, C. (2001): "Orthogonal GARCH," in Mastering risk, ed. by C. Alexander, vol. 2, pp. 21-38. London: Financial Times - Prentice Hall.

Andersen, A., T. Bollerslev, F. Diebold, and P. Labys (2003): "Modeling and forecasting realized volatility," Econometrica, 71, 579-626.

Billingsley, P. (1986): Probability and measure. New York: Wiley, second edn.

Bollerslev, T. (1986): "Generalized autoregressive conditional heteroskedasticity," Journal of Econometrics, 31, 302-327.

Bollerslev, T. (1990): "Modelling the coherence in short-run nominal exchange rates: a multivariate generalized ARCH," Review of Economics and Statistics, $72,498-505$.

Bollerslev, T., R. Engle, And J. Wooldridge (1988): "A capital asset pricing model with time varying covariances," Journal of Political Economy, 96, 116-131.

Brown, B. (1971): "Martingale central limit theorems," The Annals of Mathematical Statistics, 42, 59-66.

Burnham, K., And D. Anderson (1998): Model Selection and Inference: A Practical Information-Theoretic Approach. New York: Springer Verlag.

Clemen, R. (1989): "Combining forecasts: a review and annotated bibliography," International Journal of Forecasting, 5, 559-583.

De Santis, G., and B. Gerard (1997): "International asset pricing and portfolio diversification with time-varying risk," Journal of Finance, 52, 1881-1912.

De Santis, G., R. Litterman, A. Vesval, and K. Winkelmann (2003): "Covariance matrix estimation," in Modern investment management: an equilibrium approach, ed. by R. Litterman. London: Wiley.

Diebold, F., T. Gunther, And A. TAY (1998): "Evaluating density forecasts with application to financial risk management," International Economic Review, 39, 863-883.

Diebold, F., J. Hahn, And A. TAY (1999): "Multivariate density forecast evaluation and calibration in financial risk management: high-frequency returns on foreign exchange," The Review of Economics and Statistics, 81, 661-673.

Diebold, F., AND J. Lopez (1996): "Forecast evaluation and combination," in Handbook of Statistics, ed. by G. G.S. Maddala,and C. Rao, pp. 214-268. Amsterdam: North Holland. 
Diebold, F., ANd M. Nerlove (1989): "The dynamics of exchange rate volatility: a multivariate latent factor ARCH model," Journal of Applied Econometrics, 4, 1-21.

DrAPER, D. (1995): "Assessment and propagation of model uncertainty (with discussion)," Journal of the Royal Statistical Society, Series B, 57, 45-97.

ENGLe, R. (2002): "Dynamic conditional correlation - a simple class of multivariate generalized autoregressive conditional heteroskedasticity models," Journal of Business \& Economic Statistics, 20, 339-350.

Engle, R., V. NG, And M. Rothschild (1990): "Asset pricing with a FACTOR-ARCH covariance structure: empirical estimates for treasury bills," Journal of Econometrics, 45, 213-237.

Fernandez, C., E. Ley, And M. F. J. Steel (2001a): "Benchmark priors for bayesian model averaging," Journal of Econometrics, 100, 381-427.

Fernandez, C., E. Ley, And M. F. J. Steel (2001b): "Model uncertainty in cross-country growth regressions," Journal of Applied Econometrics, 16, 563576.

Garratt, A., K. Lee, M. H. Pesaran, And Y. Shin (2003): "Forecast uncertainties in macroeconometric modelling: an application to the UK economy," Journal of the American Statistical Association, forthcoming.

Ghysels, E., A. Harvey, and E. Renault (1995): "Stochastic Volatility," in Handbook of Statistics vol 14. Amsterdam: North Holland.

Granger, C. (1989): "Combining forecasts - Twenty years later," Journal of Forecasting, 8, 167-173.

Granger, C., And Y. JeOn (2004): "Thick modeling," Economic Modeling, 21, $323-343$.

Granger, C., And P. Newbold (1977): Forecasting economic time series. New York; London: Academic Press.

Granger, C., And M. Pesaran (2000a): "A decision theoretic approach to forecast evaluation," in Statistics and Finance: An Interface, ed. by W. Chan, W. Li,and H. Tong, pp. 261-278. London: Imperial College Press.

Granger, C., and M. Pesaran (2000b): "Economic and statistical measures of forecast accuracy," Journal of Forecasting, 19, 537-560.

Harvey, A., E. Ruiz, and N. Shephard (1994): "Multivariate Stochastic Variance Models," Review of Economic Studies, 61, 247-264.

Hendry, D., And M. Clements (2002): "Pooling of forecasts," Econometrics Journal, 5, 1-26.

Hoeting, J. A., D. Madigan, A. E. Raftery, and C. T. Volinsky (1999): "Bayesian model averaging: a tutorial," Statistical Science, 14, 382-417. 
J.P.Morgan/Reuters (1996): "RiskMetrics ${ }^{T M}$ - Technical Document, Fourth Edition,"

King, M., E. Sentana, And S. Wadhwani (1994): "Volatility and links between national stock markets," Econometrica, 62, 901-933.

Ledoit, O., P. Santa-Clara, And M. Wolf (2003): "Flexible multivariate GARCH modeling with an application to international stock markets," Review of Economics and Statistics forthcoming.

Ling, S., ANd M. McAleer (2003): "Asymptotic theory for a vector ARCHGARCH model," Econometric Theory, 19, 280-310.

Lopez, J. (1999): "Methods for evaluating value-at-risk estimates," FRBSF Economic Review, 2.

McCracken, M. (2000): "Robust out-of-sample inference," Journal of Econometrics, 99, 195-223.

Nelson, D., AND C. CAO (1992): "Inequality constraints in the univariate GARCH model," Journal of Business 83 Economic Statistics, 10, 229-235.

Pesaran, M., And S. Skouras (2002): "Decision-based methods for forecast evaluation," in A Companion to Economic Forecasting, ed. by M. Clements,and D. Hendry, pp. 241-267. Oxford: Basil Blackwell.

Pesaran, M., and A. Timmermann (1995): "Predictability of stock returns: robustness and economic significance," Journal of Finance, 50, 1201-1228.

Rosenblatt, M. (1952): "Remarks on a multivariate transformation," Annals of Mathematical Statistics, 23, 470-472.

Shephard, N. (2004): Stochastic volatility: selected readings. Oxford: Oxford University Press, forthcoming.

Sheppard, K. (2002): "UCSD_GARCH Toolbox, Version 2.0.4 19-JUN-2002," .

Stephens, M. (1970): "Use of Kolmogorov-Smirnov, Cramer-Von Mises and related statistics without extensive tables," Journal of the Royal Statistical Society, Series B (Methodological), 32, 115-122.

West, K. (1996): "Asymptotic inference about predictive ability," Econometrica, 64, 1067-1084.

Zaffaroni, P. (2003): "Estimating and forecasting volatility with large scale models: theoretical appraisal of professionals' practice," Preprint . 